\title{
How do colonial Eurasian griffon vultures prevent extra-pair mating?
}

Joan Bertran, Francesc Xavier Macià, Antoni Margalida

In colonial breeding species, preventive measures to reduce the risks of extra-pair copulations (EPCS) should reflect the actual risk perceived by males (e.g. proximity of neighbors, intrusions into the nest) mainly during the fertile period. In colonial vultures, specific studies examining the preventive measures that minimize the risks of EPCs occurring within the competitive context of colonial breeding have not been conducted. Here we tested at Eurasian Griffon Vulture (Gyps fulvus) nesting sites the intensity of paternity assurance behavior, shown as frequency and duration of within-pair copulations (WPCs), potential mate vigilance or nest attendance, and levels of aggressivity. This was measured according to the frequency of territorial intrusions and comparison of the fertile vs. the non-fertile period. Our findings suggest that the frequency of WPCs and their duration increased significantly during the presumed fertile period, regarded as the period when Griffon pairs spent significantly more time together at their nests. In addition, low levels of territorial intrusions were observed, an aggressive response of pairs towards intruders, and a relatively high presence of pairs at the nests during the fertile period. Thus, although nesting sites are subject to low exposure to EPC attempts, the increased frequency and duration of copulations during the fertile period suggests that, under pressure from the colonial breeding system, a higher rate of copulations is the most effective preventive mechanism against relative uncertainty of paternity. 
1

2

3

4

5

6

7

8

9 10

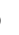

\title{
How do colonial Eurasian Griffon Vultures prevent extra-pair mating?
}

\author{
Joan Bertran $^{1}$, Francesc X. Macià ${ }^{1}$, Antoni Margalida ${ }^{2,3 *}$
}

${ }^{1}$ Bearded Vulture Study and Protection Group. Apdo. 43. E-25520 El Pont de Suert, Lleida, Spain.

${ }^{2}$ University of Lleida, Department of Animal Production (Division of Wildlife), Faculty of Life 10 ${ }^{3}$ Division of Conservation Biology. Institute of Ecology and Evolution. University of Bern. CH3012. Bern. Switzerland.

5 *Email: amargalida@prodan.udl.cat 


\section{Abstract}

19 In colonial breeding species, preventive measures to reduce the risks of extra-pair copulations

20 (EPCs) should reflect the actual risk perceived by males (e.g. proximity of neighbors, intrusions

21 into the nest) mainly during the fertile period. In colonial vultures, specific studies examining the

22 preventive measures that minimize the risks of EPCs occurring within the competitive context of

23 colonial breeding have not been conducted. Here we tested at Eurasian Griffon Vulture (Gyps

24 fulvus) nesting sites the intensity of paternity assurance behavior, shown as frequency and

25 duration of within-pair copulations (WPCs), potential mate vigilance or nest attendance, and

26 levels of aggressivity. This was measured according to the frequency of territorial intrusions and

27 comparison of the fertile vs. the non-fertile period. Our findings suggest that the frequency of WPCs and their duration increased significantly during the presumed fertile period, regarded as the period when Griffon pairs spent significantly more time together at their nests. In addition, low levels of territorial intrusions were observed, an aggressive response of pairs towards intruders, and a relatively high presence of pairs at the nests during the fertile period. Thus, although nesting sites are subject to low exposure to EPC attempts, the increased frequency and duration of copulations during the fertile period suggests that, under pressure from the colonial breeding system, a higher rate of copulations is the most effective preventive mechanism against relative uncertainty of paternity. 


\section{Introduction}

For colonially breeding bird species, competition for mates is one of the inevitable costs associated with reproduction. This may be a consequence of socio-ecological factors that make male mate-guarding an insufficient measure, or of the close proximity of neighbors facilitating situations favorable to sperm competition (Wittenberger and Hunt, 1985; Møller and Birkhead, 1993; but see Westneat and Sherman, 1997).

In raptors, proximity of conspecific breeding sites is associated with an increased risk of extra-pair copulations (EPCs), and consequently the intensity of preventive mechanisms increases with breeding density (Simmons, 1990; Arroyo, 1999; Mougeot et al., 2001; Mougeot, 2004). Paternity assurance strategies in solitary raptors, as seen in other colonial species, include (i) frequent within-pair copulations (WPCs), (ii) guarding of the partner in the nest as in the traditional mate guarding of solitary bird species, and (iii) intraspecific aggression (Negro et al., 1992; Arroyo, 1999; Mougeot et al., 2001; Garcia and Arroyo, 2002; Mougeot et al., 2006). However, paternity assurance behavior in colonial breeding species can be costly in terms of time and energy because males have to divide the time between remaining vigilant near the nest and visiting foraging sites (Birkhead and Møller, 1992; Møller and Birkhead, 1993). This would be especially relevant when food resources are temporarily scarce and scattered or distant from nesting sites. Consequently, the preventive measures to reduce the risks of EPCs should reflect the actual risk as perceived by males.

In colonial raptors, as well as aquatic and seabird species, copulation attempts away from nesting sites are unusual (Negro and Grande, 2001). In the Eurasian Griffon Vulture (Gyps fulvus), as well as other colonial vultures (Robertson, 1986), pre-laying courtship takes place mainly on nesting sites (Xirouchakis and Mylonas, 2007; Margalida and Bertran, 2010), where pairs remain most of their time. However, in this species and other colonial vultures EPCs have been recorded on nesting sites (Robertson, 1986; Xirouchakis and Mylonas, 2007). Several studies have found that breeding density and extra-pair paternity rate are positively correlated in populations of the same species (Møller and Ninni, 1998). Thus in dense colonies EPCs should be assessed as scenarios potentially advantageous in sexual competition through matings (Mougeot, 2000).

The Eurasian Griffon Vulture is a cliff-nesting, socially monogamous, colonial species that may breed in large colonies (del Hoyo et al., 1994).This species exhibits relatively high 
copulation rates over an extended period (Margalida and Bertran, 2010). Most raptors copulate extensively before egg-laying and consequently a number of copulations take place outside the fertile period (Negro and Grande, 2001). Copulations outside the fertile period probably have functions related to pair bonding, mate assessment, and territorial signaling (Newton, 1979; Tortosa and Redondo, 1992; Negro and Grande, 2001). At high breeding densities, males copulate frequently when the perceived high EPC risk is mainly derived from territorial intrusions (Møller and Birkhead, 1993). Intrusions may allow floaters to exploit EPC opportunities and to increase breeding success (Cooper et al., 2009; Moulton et al., 2013), although limited by the aggressive behavior of territorial males (Moulton et al., 2013). In strictly colonial vultures there are no specific studies examining mating behavior (copulations, extra-pair encounters, or aggressive interactions) and the preventive behaviors that minimize EPC risk. In this sense, territorial intrusions by conspecifics generally occur irregularly and are short and hidden events, being difficult to predict and observe, even in species with very high rates of extra-pair paternity (EPP; Dixon et al., 1994; Hoi et al., 2013). For this reason, observational data on male and female behavior and intrusions during the fertile period are scarce (Hoi et al., 2013).

The present case study is a contribution to reducing this deficit in our knowledge by studying mating behavior in Eurasian Griffon Vultures in a Pyrenean population (NE Spain). Our prediction is that in situations of colonial nesting, the risks of territorial intrusions and extra-pair encounters should be higher during the female fertile period and, accordingly, males should consistently show an increase in preventive behavior in that period. We tested this prediction on nesting sites by examining the frequency and potential intentionality of territorial intrusions, as well as the intensity of paternity assurance behavior and the frequency and duration of WPCs, mate vigilance, nest attendance, or levels of aggressivity. These parameters were recorded and compared in the presumed female fertile and non-fertile periods.

\section{Material and Methods}

Ethics statement

All procedures regarding observational field study (Ref. 4925-2009/2011) were conducted according to the relevant Spanish legislation and following the conditions and guidelines approved by the Department of Agriculture, Livestock and Fisheries of the Government of 
107 Catalonia. It was not possible to record data blind because our study involved focal animals in 108 the field.

\section{Study species and study area}

110 The Eurasian Griffon Vulture can nest in large colonies of over 150 pairs. Socially monogamous, 111 both male and female provide long and extensive parental care for a single egg and chick (del 112 Hoyo et al., 1994; Xirouchakis and Mylonas, 2007). On average, the species allocated 7.6 113 hour/day to food searching, being recorded the shortest foraging time in December (6.4 114 hour/day) and the longest in June (9.3 hour/day) (Xirouchakis and Andreou, 2009).

115 In breeding colonies, the distance between neighbors can be only a few meters and 116 breeding pairs only defend the immediate vicinity of the nest. Sexual activity in the species on 117 nesting sites began on average 84 days before egg-laying (Xirouchakis and Mylonas, 2007).

118 Copulations have an average duration of 48-64.6 s (see Xirouchakis and Mylonas, 2007;

119 Margalida and Bertran, 2010); they are conspicuous and accompanied by loud cries (Margalida 120 and Bertran, 2010). In this and similar species, copulations at the nest site probably have 121 functions other than fertilization, such as territorial signaling (see Robertson, 1986; Negro and 122 Grande, 2001).

123 We conducted fieldwork during the breeding seasons (pre-laying periods) of 2008 - 2011 124 in the Catalonian foothills of the Pyrenees (NE Spain), in six colonies with 33 breeding pairs 125 (Table 1). The size of the colonies (maximum distance from one side to the other of the colonies) 126 ranged approximately between 50 and $175 \mathrm{~m}$. In Catalonia the breeding population in 2009 was 127 estimated at 1115 breeding pairs. The high densities of avian scavengers in Catalonia are a result 128 of the extensive livestock populations (Margalida et al., 2007).

Data collection and observation methods

131 In all years, observations began during the first week of November, coinciding with the period 132 previous to the first copulation attempts (Margalida and Bertran, 2010) and concluded with the 133 laying period (January-February). In each colony we carried out a simultaneous monitoring of 134 five pairs, except in one colony in which nests were very close to each other, enabling us to 135 follow a total of eight pairs. We carried out a weekly visit per colony, thus conducting a total of $136342.50 \mathrm{~h}$ of observations in 59 fieldwork days (average per colony $57.1 \mathrm{~h}$, range $43.5-83.25 \mathrm{~h}$ ). 
In each colony the criteria used to select breeding pairs to be monitored were established

138 by taking into account the higher nest concentrations and focal nests that had optimal observation

139

140

141

142

143

144

145

146

147

148

149

150

151

152

153

154

155

156

157

158

159

160

161

162

163

164

165

166

167 conditions. In all cases, the distances were $<100 \mathrm{~m}$ and only in a case the largest distance was approximately around $200 \mathrm{~m}$. When possible, we also recorded the birds' activities away from the nests (e.g. material collecting for the nests). Birds were observed with a 20-60 x telescope at a distance of 100-200 $\mathrm{m}$ from the rock face where the nests were located.

The Griffon Vultures in this study were not marked individually, though this species shows virtually no sexual dimorphism (del Hoyo et al., 1994). Consequently, to identify nesting pairs and to avoid the risk of counting copulations that were possible cases of EPCs by intruders, we relied on observations of typical behavior of the pairs involved in copulations, as well as contributions to nest-material gathering, arrangement of the nest, or nest defense (see Ferrero et al., 2003; Margalida and Bertran, 2010). Individual characteristics of their plumage (perched and in flight) were also used to identify the partners (see Bertran and Margalida, 1999; Margalida and Bertran, 2000a). In addition, the Eurasian Griffon Vulture is a territorial species, intruders being aggressively expelled from the immediate nest surroundings during the fertile period (Xirouchakis and Mylonas, 2007; see also Results). We considered that such intrusions would occur furtively and be brief in duration, since copulations in these vultures are conspicuous because of their long duration and being marked with loud cries (Margalida and Bertran, 2010). To minimize possible replication in the copulation frequencies, we took into account the time when birds remained together before or after intra-pair matings. In this way, $74 \%(n=171)$ of sexual interactions observed were accompanied by habitual behavior of pairs at nesting sites (i.e. nest-building, delivering material, arranging the nest, nest defense), and so we were able to rule out those cases involving foreign individuals. In the remaining 26\% $(n=60)$, matings were "neutral" without any behavior that could be associated with the resident pairs. Thus of the 60 cases of "neutral" mountings, we discarded those in which the individuals remained together (until one left the nest) for more than $30 \mathrm{~min}$, which left 16 interactions which showed an average presence of birds together of $19.9 \mathrm{~min}$ (range: 14-28 min). In all these cases copulations ended with apparent success and behaviors that in any way indicated the existence of EPCs were not observed (see Results). On the contrary, the EPC attempts observed during a no systematic monitoring outside nesting sites $(20-200 \mathrm{~m})$ could be partially underestimated. However, these EPC attempts were confirmed because when males abandoned nests, their partners remained in 
168 them, and then males interacted with other females. In this sense, except in one colony, the 169 observations were carried out by two observers. Therefore, events in and out the nest were 170 followed simultaneously.

171 During observations of focal nests, for each observed copulation attempt we recorded: (1)

172 the identity of the pair involved; (2) whether the copulation was successful or not (i.e. whether 173 cloacal contact was achieved during mount); (3) the duration of copulation attempts (in seconds) 174 measured with a stopwatch, and all included mounting movements. The frequency of copulations 175 was estimated as the number of attempts per hour. We quantified for each pair/colony the 176 percentage of time spent by one or both members of the pair within the breeding territory (nest 177 site and nearby area). We recorded the frequency of territorial intrusions (number of events/h) 178 and when these occurred at nests where one or both members of the pair were present. We also 179 recorded for each intrusion if it ended with aggression and the levels of aggressivity (i.e. physical 180 contact or not).

181 The frequencies obtained for copulation behavior, nest attendance, and territorial

182 intrusions were combined in two differentiated time periods, pre-fertile (PF) and fertile (F).

183 Studies on copulatory behavior in raptors suggest that the fertile period can begin about 12 days

184 before egg-laying (Bird and Buckland, 1976; Negro et al., 1992; Mougeot, 2000). Here, we

185 assumed a presumed fertile period of $<14$ days before laying, dating backwards from egg-laying

186 (day 0 was considered as the egg-laying date). Egg-laying dates were determined by direct

187 observation of adult behavior in the nest.

Data analysis

190 All of the statistical analyses were carried out to a significance level of 0.05 . The differences in 191 the amount of time spent by males and females at the nest, intrusions, copulation attempts, and 192 copulation duration between periods (PF vs F) were tested using the Wilcoxon test for matched 193 pairs. Values presented are the mean \pm standard deviation (SD).

\section{Results}

Within-pair copulations

197 We observed a total of 231 sexual interactions on the nests. Copulation attempts were observed 198 in $31(93.9 \%)$ of the 33 pairs monitored. In 210 (90.9\%) copulations attempts we were able to 
199

200

201

202

203

204

205

206

207

208

209

210

211

212

213

214

215

216

217

218

219

220

221

222

223

224

225

226

227

228

discern if these were successful, which $93.3 \%(n=196)$ were. Non-successful mating attempts were caused by female reluctance.

The mean frequency of copulation attempts (attempts/hour) was significantly higher during the fertile period (PF: $0.10 \pm 0.03$ vs. F: $0.33 \pm 0.05, n=231$; Wilcoxon test: $z=2.207, P$ $=0.027$, Figure 1a). In addition, the time duration of the behaviorally successful copulations (data obtained from five colonies, $n=120$ ), were significantly more prolonged in this period (PF: $33.26 \pm 4.16$ vs. F: $43.96 \pm 9.55$; Wilcoxon test: $z=2.023, P=0.043$, Figure $1 \mathrm{~b}$ ).

\section{Nest presence}

The average proportion of time that one of the members of the pair was present at the nest did not vary significantly between the two periods (PF: $23.67 \pm 6.12 \%$ vs. F: $30.42 \pm 5.25 \%$;

Wilcoxon test: $z=1.572, P=0.115)$. On the contrary, the average presence of the two individuals together increased significantly during the fertile period (PF: $32.57 \pm 9.10 \% \mathrm{vs}$. F: $47.67 \pm 3.84 \%$; Wilcoxon test: $z=2.201, P=0.027$; Figure $2 \mathrm{a}$ ).

\section{Nest defense behavior}

Nest intrusions were observed in $30(90.9 \%)$ of the 33 monitored pairs; $14.4 \%(n=15)$ of the agonistic interactions ended with physical aggression. The intrusions $(n=104)$ occurred irrespective of, and in similar proportions to, whether one partner of the pair was present at the nest $(45.2 \%)$ or both $(54.8 \%)$. Similar intrusion proportions were observed in both the pre-fertile and fertile periods (PF: partners in the nest: one $45.7 \%$, both $54.3 \%, n=70$; F: one $44.1 \%$, both $55.9 \% \mathrm{~N}=34 ; \chi^{2}{ }_{1}=0.584, P=0.445$ ). The average frequency of intrusions (intrusions/hour) was marginally significantly higher in the fertile period (PF: $0.05 \pm 0.03$ vs. F: $0.11 \pm 0.04$; Wilcoxon test: $z=1.941, P=0.052$; Figure $2 b$ ).

In two of the six studied colonies we observed EPCs. These EPCs involved four males $(12.1 \%)$ and a female $(3 \%)$, being $3.3 \%$ of observed copulations $(n=239)$. The EPCs were effectuated by males in neutral sites in the colonies at distances of between 20 and $200 \mathrm{~m}$ from their nests. In four of the cases, the interactions occurred while males were absent collecting nest material. One case of successful EPC is highlighted which involved a male and a female from neighboring nests (separated by $10 \mathrm{~m}$ ), both during their respective fertile periods, while 
229 collecting material for their nests. All extra-pair encounters were brief, and in seven of the eight

230 cases the copulation attempts by males were rejected by the females involved.

231

\section{Discussion}

233 Within-pair copulations

234 Usually all raptors exhibit high rates of copulation during an extended period of time (Negro and

235 Grande, 2001), and in some species the frequency of intra-pair copulations increases with the

236 breeding density (Simmons, 1990; Korpimäki et al., 1996; Arroyo, 1999; Mougeot, 2004).

237 However, there is great interspecific variation and it is not always the case that colonial species

238 show higher copulation rates than solitary species, which disagrees with the hypothesis of sperm

239 competition, suggesting that phylogenetic aspects should be also evaluated (Arroyo, 1999). For

240 example, Griffon Vultures averaging 71.7 copulations per clutch and an average frequency of 1.2

241 copulation/day (Margalida and Bertran, 2010) show a frequency lower than the average

242 copulatory behavior observed in other raptors (215 copulations per clutch and 11 per day;

243 Arroyo, 1999). However, our comparative results between the different stages of the pre-laying

244 period show that both, the relative frequency of intra-pair copulation and its duration, increased

245 significantly during the presumed fertile period, being consistent with the hypothesis of paternity

246 insurance/sperm competition (Birkhead and Møller, 1998; Mougeot, 2000; Komdeur, 2001;

247 Mougeot et al., 2001; Garcia and Arroyo, 2002). The duration of copulations is associated with

248 an increased sperm transfer mechanism to dilute the sperm of other males in situations of sperm

249 competition (Birkhead and Møller, 1992). There is unfortunately little information for raptors,

250 and a longer duration of copulation could result in a greater transfer of sperm or ensure cloacal

251 contact (Mougeot, 2004). For example, an experimental study in the semi-colonial Montagu's

252 Harrier (Circus pygargus) showed that males increase both WPCs and copulation duration in

253 simulated situations of sperm competition.

254

255 Nest attendance, nest defense, and territorial intrusions

256 Griffon pairs spent significantly more time together in the nest in the presumed fertile period.

257 Although raptor males are considered to be inefficient in mate guarding, in some species they

258 seek to maximize their time with females on nesting sites during their fertile period (Birkhead

259 and Møller, 1992). Specifically, in some territorial vultures like Egyptian Vulture (Neophron 
260 percnopterus) and Bearded Vulture (Gypaetus barbatus) (Donázar et al., 1994; Bertran and

261 Margalida. 1999) males significantly increased their time at the nest together with females in 262 mate vigilance behavior. This can be facilitated because in these species, as occur in Griffon 263 Vultures, males do not feed their partners (courtship feeding) during the fertile period (Margalida 264 and Bertran, 2000b). However, a previous study showed that male Griffons did not significantly 265 increase their time with females as the time of egg-laying approached (Margalida and Bertran, 266 2010). The possible absence of mate guarding in this species, which covers large areas searching 267 for an unpredictable and scarce food resource, may be due to a conflict arising from increasing 268 surveillance of the nest and reduced foraging efficiency (Møller, 1987; Westneat, 1994). In fact, 269 Griffon Vultures annually invest on average about 58-75\% of their time to foraging activities 270 (Leconte, 1977; Xirouchakis and Andreou, 2009). However, the male presence at the nest and 271 its surroundings during the hypothetical fertile period has to be relevant because males collect 272 most of the material for the nest, which takes place within two weeks of egg-laying. In this 273 period we observed the $79.4 \pm 14.8 \%$ of the total deliveries (range $58.8-100 \%, n=258$ ) in which 274 in the 68.4\% $(n=79)$ were involved the males (unpubl. data; see also Xirouchakis and Mylonas, 275 2007).

Intrusions occurred in $90.9 \%$ of the nests monitored, with a tendency to increase 277 (although statistically marginal) during the presumed fertile period. However the level of intrusions observed $(0.05$ and $0.11 / \mathrm{h}$ during the pre-fertile and fertile periods, respectively) is low if we hypothetically consider this colonial species to be prone to EPC attempts. For example, in some semi-colonial raptor species like Red Kite (Milvus milvus) territorial intrusions by males are relatively frequent during the fertile period (Mougeot, 2000). Intrusions by outsiders

282 frequently occur for reasons associated with territoriality and the search for vacant sites, but in the female fertile period they can involve intrasexual competition (Møller, 1987). Our study does not show this clearly, since it would be expected that males should seek EPCs in other nests, taking advantage of this opportunity when females were alone. However, the results show that the similar numbers of intrusions occurred when the nest was occupied by one member of the pair $(45.2 \%)$ or both $(54.8 \%)$, and in both cases the intruders were expelled, a relatively high proportion (14.4\%) of them by physical aggression. In this species, attempts to steal nest material from neighboring sites can be a major cause of intrusions. These actions (which can also occasionally include nest destruction) occur mostly when nests are unguarded, but can also 
291 happen when they are occupied by pairs, and can coincide with the female fertile period (authors

292 unpubl. data; see also Xirouchakis and Mylonas, 2007).

293

294

295

296

297

298

299

300

301

302

303

304

305

306

307

308

309

310

311

312

313

314

315

316

317

318

319

320

321

\section{Extra-pair copulations}

The frequency of copulations outside the pair bond in socially monogamous species obliges males to adopt preventive strategies to avoid the risk of cuckoldry (Birkhead and Møller 1992; Hoi et al., 2013). In this sense, it is difficult to disentangle when females use male absence to obtain EPCs and when they suffer male harassment and coercion in forced EPCs (Dunn et al., 1999; Low, 2004, 2005).

Studies on the copulatory behavior of raptors showing the frequency of EPCs are relatively scarce: 7\% (see Arroyo, 1999; Mougeot, 2004) of the 287 known species (Newton 1979). The percentage values of EPCs found in the studied species vary between 0 and $7.3 \%$ (Mougeot, 2004; see also Arroyo, 1999). With respect to EPP (extra-pair paternity), in species such as Swainson's Hawk (Buteo swainsoni) the frequency is low, occurring in 5\% of chicks and $7 \%$ of nests (Briggs and Collopy, 2012). The percentage of EPCs obtained in our study (3.3\% of copulations, $n=239$ ) coincides with values documented in Xirouchakis and Mylonas (2007), but unlike these authors we did not confirm episodes of EPCs on nesting sites. The fact that EPC attempts were observed in sites not surveyed systematically (20-200 m from the nests) suggests the possibility that the actual frequency of EPCs was greater than obtained. EPC attempts occurred in two (33\%) of the six colonies studied and involved only $12.1 \%$ of males and $3 \%$ of females monitored ( $n=33$ breeding pairs) and in most attempts (88\%) EPCs were rejected by females.

Levels of EPCs in other vulture species are also low: $0.05 \%$ in Cape Griffon (Gyps coprotheres) (Mundy et al., 1992); 0.52\% in Bearded Vulture (Bertran and Margalida, 1999); $2.6 \%$ in Egyptian Vulture (Donázar et al., 1994). But this low frequency of EPCs contrasts with the $23 \%$ obtained in a reintroduced population of California Condor (Gymnogyps californianus) (Mee et al., 2004). These authors argued that EPCs may be enhanced in this reintroduced population because of increasing social interactions due to food concentration at a few feeding stations, limited mate choice, and a high level of inbreeding (Mee et al., 2004).

Extra pair fertilizations (EPFs) as a consequence of EPCs have been detected at low levels in the raptor species studied (1-5\% of young or broods; Mougeot, 2004; Rosenfield et al., 
322 2015). Based on the idea that females control the success of copulations, we can expect that in

323 long-lived species where males invest heavily in reproduction (e.g. colonial seabirds and raptors)

324 they obviously tend to restrict EPCs, to avoid jeopardizing the male investment (Whittingham et

325 al., 1992; Westneat and Sargent, 1996; Petrie and Kempenaers, 1998; Sheldon and Ellegren,

326 1998; Briggs and Collopy, 2012; Wojczulanis-Jakubas et al., 2014). In this regard, in raptors that

327 nest in open country the fact that extra-pair interactions are visible or audible at long distances

328 has also been suggested as a limiting factor in EPCs (Korpimäki et al., 1996). Finally, for

329 colonial monogamous bird species copulating during long time periods, acoustic signals are

330 important for recognition within the pair (McArthur, 1982). In addition, when copulating Griffon

331 pairs emit loud cries it has been suggested that they act as signaling territorial occupation of the

332 nest (Robertson, 1986; Negro and Grande, 2001), though this copulatory activity may also act as

333 a warning (Margalida and Bertran, 2010).

334 In conclusion, contrary to expectations our findings show that nesting sites are scenarios

335

336

337

338

339

340

341

342

343

344

345

346

347

348

349

350

351

with low frequencies of EPC attempts due to: i) low levels of territorial intrusions which, when they occur, are not necessarily associated with sperm competition; ii) the aggressive response of pairs facing territorial intrusions; iii) the relatively high presence of pairs in the nests (on average 47.7\%) during the presumed fertile period. However, the copulatory behavior of this species in the fertile period (increased frequency and duration of copulations) suggests that under pressure from the colonial breeding system (proximity of conspecifics and/or males that may not always stay close to their mates), a higher rate of copulation is the best preventive mechanism against relative uncertainty of paternity. On the other hand, the results suggest that males seem to make EPC attempts in sites far from the nest, coinciding with the collection of nest material. Under these circumstances, an increase in copulation attempts during the fertile period suggest that, for males, this is probably the most effective way to obtain the last copulations with their mates before egg-laying (Birkhead and Møller, 1992) and also to ensure their paternity. Griffon Vulture males play all or nothing on investment for a single egg and chick per breeding attempt, where besides their contribution in parental care is indispensable. In consequence, paternity loss would be too expensive for Griffon Vulture males.

\section{Acknowledgments}


352 We thank Karl Schulze-Hagen, Tim R. Birkhead and two anonymous reviewers for their

353 comments on improving the manuscript and Brian Hillcoat for revision of the English style.

354

355

356

357

358

359

360

361

362

363

364

365

366

367

368

369

370

371

372

373

374

375

376

377

378

379

380

381

382

\section{References}

Arroyo BE. 1999. Copulatory behavior of semi-colonial Montagu's harriers. Condor 101:340-346.

Bertran J, Margalida A. 1999. Copulatory behavior of the Bearded vulture. Condor 101:161-164.

Bird DM, Buckland RB. 1976. The onset and duration of fertility in the American kestrel. Canadian Journal of Zoology 54:1595-1597.

Birkhead TR. 1988. Behavioral aspects of sperm competition in birds. Advances Study Behaviour 18:35-72.

Birkhead TR, Møller AP. 1992. Sperm competition in birds: evolutionary causes and consequences. Academic Press, London.

Birkhead TR, Møller AP. 1998. Sperm Competition and Sexual Selection. Academic Press, London.

Birkhead TR, Atkin L, Møller AP. 1987. Copulation behaviour in birds. Behaviour 101:101-138.

Briggs CW, Collopy MW. 2012. Extra-pair paternity in Swainson's Hawks. Journal of Field Ornithology 83:41-46.

Cooper NW, Murphy MT, Redmong LJ, Dolan AC. 2009. Density-dependent age at first reproduction in the Eastern Kingbird. Oikos 118:413-419.

del Hoyo J, Elliott A, Sargatal J (eds.). 1994. Handbook of the Birds of the World.

Vol. 2. New World Vultures to Guineafowl. Lynx Edicions, Barcelona.

Dixon A, Ross D, O’Malley SLC, Burke T. 1994. Paternal investment inversely related to degree of extra-pair paternity in the reed bunting. Nature 371:698 -700 .

Donázar JA, Ceballos O, Tella JL. 1994. Copulation behaviour in the Egyptian Vulture Neophron percnopterus. Bird Study 41:37-41.

Dunn PO, Afton AD, Gloutney ML, Alisauskas RT. 1999. Forced copulation results in fewer extra-pair fertilizations in Ross's and lesser snow geese. Animal 
383

384

385

386

387

388

389

390

391

392

393

394

395

396

397

398

399

400

401

402

403

404

405

406

407

408

409

410

411

412

413

Behaviour 57:1071-1081.

Ferrero JJ, Grande JM, Negro JJ. 2003. Copulation behavior of a potentially doublebrooded bird of prey, the Black-Winged Kite (Elanus caeruleus). Journal of Raptor Research 37: 1-7.

García JT, Arroyo BE. 2002. Intra- and interspecific agonistic behaviour in sympatric harriers during the breeding season. Animal Behaviour 64:77-84.

Hoi H, Kristofík J, Darolová A. 2013. Experimentally simulating paternity uncertainty: Immediate and long-term responses of male and female reed warblers Acrocephalus scirpaceus. PLoS ONE 8:e62541.

Komdeur J. 2001. Mate guarding in the Seychelles warbler is energetically costly and adjusted to paternity risk. Proceedings of the Royal Society of London B 268: 2103-2111.

\section{Korpimäki E, Lahti K, May CA, Parkin DT, Powel GB, Tolonen P, Wetton JH.} 1996. Copulatory behaviour and paternity determined by DNA fingerprinting in kestrels: effect of cyclic food abundance. Animal Behaviour 51:945-955.

Leconte M. 1977. Étude de la reproduction du vautour fauve dans les Pyrénées occidentales. Le Courbageot 4: 8-19.

Low M. 2004. Female weight predicts the timing of forced copulation attempts in stitchbirds, Notiomystis cincta. Animal Behaviour 68:637-644.

Low M. 2005. Female resistance and male force: context and patterns of copulation in the New Zealand stitchbird Notiomystis cincta. Journal of Avian Biology 36:436448.

Margalida A, Bertran J. 2000a. Breeding behaviour of the Bearded Vulture Gypaetus barbatus: minimal sexual differences in parental activities. Ibis 142: 225-234.

Margalida A, Bertran J. 2000b. Nest-building behaviour of the Bearded Vulture (Gypaetus barbatus). Ardea 88:259-264.

Margalida A, Bertran J. 2010. Copulatory behaviour in the colonial Eurasian Griffon Vulture Gyps fulvus. Journal of Ethology 28:179-182.

Margalida A, García, D, Cortés-Avizanda A. 2007. Factors influencing the breeding density of Bearded Vultures, Egyptian Vultures and Eurasian Griffon Vultures in Catalonia (NE Spain): management implications. Animal Biodiversity and Conservation 30:189-200. 
414 Mc Arthur P. 1982. Mechanisms and development of parent-young recognition in the

415

416

417

418

419

420

421

422

423

424

425

426

427

428

429

430

431

432

433

434

435

436

437

438

439

440

441

442

443

444 pinyion jay (Gymnorhinus cyanocephalus). Animal Behaviour 30:62-74.

\section{Mee A, Austin G, Barth M, Beestman C, Smith T, Wallace M. 2004. Courtship} behaviour in reintroduced California Condors: evidence for extra-pair copulations and female mate guarding. Pp. 75-82 in Proceedings of VI World Conference on Birds of Prey and Owls (RD Chancellor and B-U. Meyburg, eds.). World Working Group and Birds of Prey and Owls/MME-Birdlife. Hungary.

Møller AP. 1987. Copulation behaviour in the Goshawk Accipiter gentilis. Animal Behaviour 35:755-763.

Møller AP, Birkhead TR. 1993. Cuckoldry and sociality: a comparative study in birds. American Naturalist 142:118-140.

Møller AP, Ninni P. 1998. Sperm competition and sexual selection: a meta-analysis of paternity studies of birds. Behavioural Ecology and Sociobiology 43:345-358.

Mougeot F. 2000. Territorial intrusions and copulation patterns in red kites, Milvus milvus, in relation to breeding density. Animal Behaviour 59:633-642.

Mougeot F. 2004. Breeding density, cuckoldry risk and copulation behaviour during the fertile period in raptors: a comparative analysis. Animal Behaviour 67:1067- 1076.

Mougeot F, Arroyo BE, Bretagnolle V. 2001. Decoy presentations as a means to manipulate the risk of extrapair copulation: an experimental study in a semicolonial raptor, the Montagu's harrier (Circus pygargus). Behavioral Ecology 12:1-7.

Mougeot F, Arroyo BE, Bretagnolle V. 2006. Paternity assurance responses to first -year and adult male territorial intrusions in a courtship-feeding raptor. Animal Behaviour 71:101-108.

Moulton LL, Linz GM, Bleier WJ. 2013. Responses of territorial and floater male Red-winged Blackbirds to models of receptive females. Journal of Field Ornithology 84:160- 170.

Mundy P, Butchart D, Ledger J, Piper S. 1992. The Vultures of Africa. Acorn Books and Russel Friedman Books, Johannesburg, South Africa.

Negro JJ, Grande JM. 2001. Territorial signalling: a new hypothesis to explain frequent copulation in raptorial birds. Animal Behaviour 62:803-809.

Negro JJ, Donázar JA, Hiraldo F. 1992. Copulatory behaviour in a colony of lesser 
kestrels: sperm competition and mixed reproductive strategies. Animal Behaviour 43:

446 921-930.

Newton I. 1979. Population Ecology of Raptors. T. and A.D. Poyser, Berkhamstead.

Petrie M, Kempenaers B. 1998. Extra-pair paternity in birds: explaining variation between species and population. Trends in Ecology and Evolution 13:52-58.

450

451

452

453

454

455

456

457

458

459

460

461

462

463

464

465

466

467

468

469

470

471

472

473

474

475

Robertson A. 1986. Copulations throughout breeding in a colonial Accipitrid vulture. Condor 88:535-539.

Rosenfield RN, Sonsthagen SA, Stout WE, Talbot SL. 2015. High frequency of extrapair paternity in an urban population of Cooper's Hawks. Journal of Field Ornithology 86:144-152.

Sheldon BC, Ellegren H. 1998. Paternal effort related to experimentally manipulated paternity of male collared flycatchers. Proceedings of the Royal Society of

B 265:1737-1742.

Simmons R. 1990. Copulation patterns of African marsh harriers: evaluating the paternity assurance hypothesis. Animal Behaviour 40:1151-1157.

Tortosa FS, Redondo T. 1992. Frequent copulations despite low sperm competition in white storks (Ciconia ciconia). Behaviour 121:288-314.

Westneat DF. 1994. To guard mates or go forage: conflicting demands affect the paternity of male red-winged blackbirds. American Naturalist 144:343-354.

Westneat DF, Sargent RC. 1996. Sex and parenting: the effects of sexual conflict and parentage on parental strategies. Trends in Ecology and Evolution 11:87-91.

Westneat DF, Sherman PW. 1997. Density and extra-pair fertilizations in birds: a comparative analysis. Behavioural Ecology and Sociobiology 41:205-215.

Whittingham LA, Taylor PD, Robertson RJ. 1992. Confidence of paternity and male parental care. American Naturalist 139:1115-1125.

Wittenberger JF, Hunt Jr. GF. 1985. The adaptive significance of coloniality in birds. Pp. 1-74 in Avian Biology, vol. 8 (eds. Farner DS, King JR, Parkes, KC), Academic Press, New York.

Wojczulanis-Jakubas K, Jakubas D, Chastel O. 2014. Different tactics, one goal: initial reproductive investments of males and females in a small Arctic seabird. Behavioural Ecology and Sociobiology 68:1521-1530. 
476 Xirouchakis SM, Andreou G. 2009. Foraging behaviour and flight characteristics of

477 Eurasian griffons Gyps fulvus in the island of Crete, Greece. Wildlife Biology

15: $37-$

47852.

479 Xirouchakis SM, Mylonas M. 2007. Breeding behaviour and parental care of the

480

Griffon Vulture Gyps fulvus on the island of Crete (Greece). Ethology Ecology and

481 Evolution 19:1-26. 
482 Table 1. Descriptive data of the colony size, numbers of pairs controlled and fieldwork invested 483 during the study of sexual activity on Eurasian Griffon Vultures.

\begin{tabular}{|l|l|l|l|l|}
\hline Colony & Pairs controlled & Days & Hours & Colony size \\
\hline 1 & 5 & 11 & 66.5 & 16 \\
\hline 2 & 5 & 10 & 60 & 29 \\
\hline 3 & 8 & 9 & 45.25 & 40 \\
\hline 4 & 5 & 10 & 43.5 & 19 \\
\hline 5 & 5 & 9 & 44 & 9 \\
\hline 6 & 5 & 9 & 83.25 & 8 \\
\hline Total & 33 & 57 & 342.5 & \\
\hline
\end{tabular}

484

485 
486 Figures 
487 Figure 1. Differences in the copulation frequency (a) (attempts per hour \pm SD) and time duration 488 (b) (seconds \pm SD) between the presumed pre-fertile and fertile periods (for details see 489 Methods).
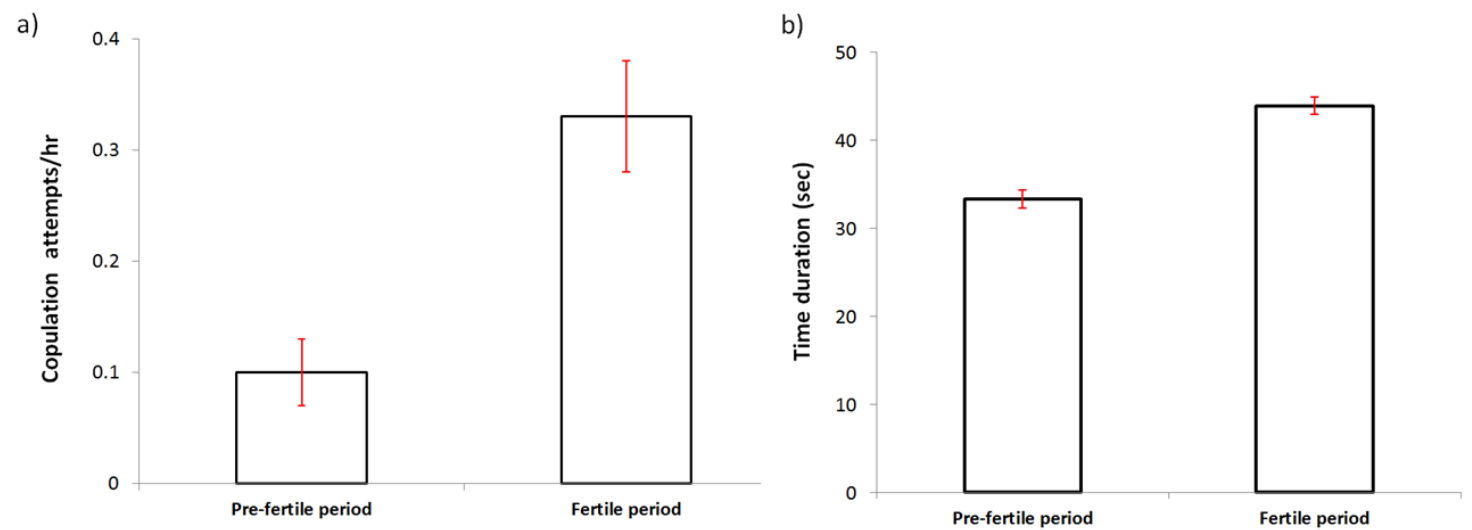

490 
491 Figure 2. Differences in the percentage of presence (a) ( \pm SD) of breeding pairs at nests and the 492 frequency of intrusions per hour (b) ( \pm SD) at nest sites by foreign individuals between the 493 presumed pre-fertile and fertile periods (for details see Methods).

494

a)

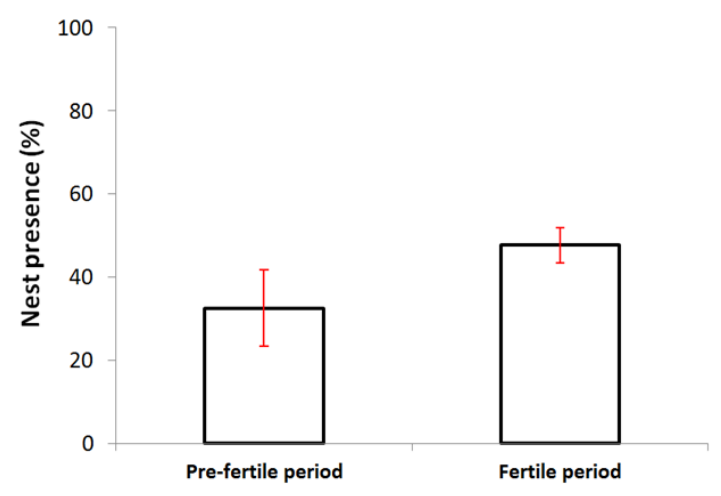

b)

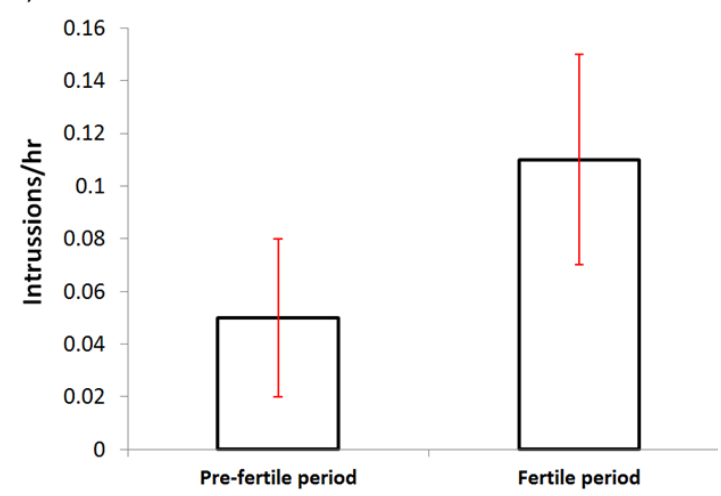

495

496 